\title{
J.L. GOÑI SEIN y B. RODRÍGUEZ SANZ DE GALDEANO, Adaptación y reubicación laboral de trabajadores con limitaciones psicofísicas, Thomson Reuters Aranzadi (Cizur Menor, 2015), 311 págs.
}

\author{
IVÁN VIZCAÍNO RAMOS \\ Profesor Doctor Contratado Indefinido \\ EU de Relaciones Laborales de Coruña \\ Centro adscrito de la Universidad de A Coruña
}

El Profesor GOÑI SEIN, Catedrático de Derecho del Trabajo de la Universidad Pública de Navarra, es un Maestro interesado desde siempre en el asunto de la eventual incapacidad física/psíquica del trabajador asalariado, obrando a este respecto en su curriculum un artículo clásico publicado en la Revista Española de Derecho del Trabajo en 1982, en el que analizaba el tema desde el ángulo del despido. Es igualmente uno de los grandes especialistas españoles en la complejísima parcela del Derecho de la prevención de riesgos laborales, cuya maestría en ella le ha permitido utilizarla aquí como palanca, al efecto de dar un salto cualitativo, verdadero paso de gigante, que trasciende el Derecho de la seguridad y salud laboral, creando una monografía rigurosamente transversal compuesta por piezas muy dispersas de un verdadero puzzle jurídico, aparentemente muy difíciles de casar. El Maestro euskaldún lo es también, en fin, porque ha formado discípulos, que han alcanzado ya el rango de oficiales (en el sentido clásico de tratarse de personas plenamente conocedoras ya de su oficio de profesores universitarios) en el taller "gremial» que dirige el Maestro en la Universidad Pública de Navarra desde hace un buen montón de años, resultando ser aquí la «oficial» en cuestión, su discípula la Profesora Beatriz RODRÍGUEZ SANZ DE GALDEANO. Ambos son coautores de este interesantísimo libro, que tanto me complace reseñar. Según consta en él, «el estudio se ha realizado en el marco de un Proyecto de I+D titulado "La adaptación del puesto de trabajo y la reubicación laboral de los trabajadores especialmente sensibles" (DER 2012-37872), dirigido por José Luis GOÑI SEIN y financiado con cargo al Plan Nacional de Investigación».

En realidad, esta obra es un estudio transversal del trabajador con limitaciones psicofísicas, que pretende hilar tres especies concretas de dicho género. En primer lugar, la relativa a lo que nuestros autores denominan «trabajadores sensibles», una noción anclada en el artículo 25 de la Ley de prevención de riesgos laborales. En segundo 
lugar, la relativa a los «trabajadores discapacitados», de moda y de plena actualidad hoy, tras la entrada en vigor del Real Decreto Legislativo 1/2013, aprobando la Ley general de derechos de las personas con discapacidad. En tercer lugar, la relativa a los «trabajadores incapacitados permanentes», anclada en nuestra vigente legislación de seguridad social, en relación con la cual afirman nuestros autores - con una escrupulosidad científica que les honra- que «la obra se ha cerrado a 6 de noviembre de 2015, justo después de la aprobación de los Textos Refundidos de la Ley del Estatuto de los Trabajadores (Real Decreto Legislativo 2/2015, de 23 de octubre) y de la Ley General de Seguridad Social (Real Decreto Legislativo 8/2015, de 30 octubre) por lo que se ha dado cumplida referencia de dichas normas, aun cuando esta última no tenga prevista su entrada en vigor hasta el 2 de enero de 2016». La gran aportación de la obra, formalizada en el Capítulo I de la misma, se refiere a la ideación de un concepto genérico (que también podría denominarse concepto-madre o concepto-base) de trabajadores con limitaciones psico-físicas, pues los tres conceptos específicos recién citados «no abarcan todas las situaciones de discapacidad en el ámbito laboral», por lo que - prosiguen nuestros autores - «el concepto de discapacidad laboral aquí planteado pretende abordar la problemática de aquellos trabajadores que por algún tipo de limitación no pueden desempeñar su trabajo de acuerdo con un rendimiento normal y en condiciones de seguridad». Este planteamiento teórico hace brillar, una vez más, la afirmación de los grandes clásicos universitarios (yo la he visto escrita, por ejemplo, en una publicación del Maestro Don Manuel ALONSO OLEA), relativa a que el mejor libro práctico es siempre un gran libro teórico. Aquí el interés práctico de la obra de nuestros autores se hace patente en los Capítulos IV, V y VI, en los que los Profesores GOÑI SEIN y RODRÍGUEZ SANZ DE GALDEANO han logrado averiguar «en cada categoría hasta dónde llega la obligación empresarial de adaptar el puesto de trabajo o de realizar ajustes y cuáles son las condiciones que deben guiar la adopción de dichas medidas», así como "cuáles son las consecuencias de la imposibilidad de aplicar medidas de ajuste y también qué ocurre cuando, aun siendo posible, el empresario se niega a su adopción».

Por lo demás, es claro no sólo que se trata de una monografía espléndida (con todo su interés doctrinal-conceptual, pero con marcadísima utilidad práctica), sino también de una obra jurídica que sólo cabe adjetivar igualmente como obra clásica. Lo prueba, en el citado Capítulo I de la misma, la existencia de un epígrafe específico que resultaría injusto no jalear o reseñar - sobre «El concepto de discapacidad en Derecho comparado». Se afirma allí, en lo más esencial, que «EEUU y Reino Unido son los países que atesoran una mayor tradición en la intervención legislativa para evitar la discriminación por razón de discapacidad»; y también, que «en EEUU la American Disability Act (en adelante ADA) del año 1990 y reformada en el año 2008, es la norma de referencia», resultando ser su pendant en el Reino Unido la Disability Discrimination Act del año 1995 sustituida en el año 2010 por la Equality Act». En fin, esta obra de los Profesores GOÑI SEIN y RODRÍGUEZ SANZ DE GALDEANO saca a la luz una vez más, con este planteamiento suyo, la arrinconada (y a veces, casi olvidada) disposición adicional tercera de nuestro Código Civil de 1889, que se encuentra en la base misma de todos los estudios españoles de Derecho comparado, también los de Derecho comparado del Trabajo y de la Seguridad Social. En esto, nuestro Maestro euskaldún es también verdadero Maestro al cuadrado, cabiendo recordar con agradecimiento una contribución suya a nuestro Anuario Coruñés de Derecho Comparado del Trabajo, verdaderamente magistral, publicada en el volumen II, correspondiente al año 2010. 